\title{
Preparing the Next Generation of Instructional Designers: A Cross-Institution Faculty Collaboration
}

\author{
Patricia J. Slagter van Tryon \\ East Carolina University \\ Jason K. McDonald \\ Brigham Young University, jason_mcdonald@byu.edu \\ Atsusi Hirumi \\ University of Central Florida
}

Follow this and additional works at: https://scholarsarchive.byu.edu/facpub

Part of the Instructional Media Design Commons

\section{Original Publication Citation}

Slagter van Tryon, P.J., McDonald, J. \& Hirumi, A. (2018). Preparing the next generation of instructional designers: a cross-institution faculty collaboration. Journal of Computing in Higher Education. Volume 30, Issue 1, 125-153

\section{BYU ScholarsArchive Citation}

Slagter van Tryon, Patricia J.; McDonald, Jason K.; and Hirumi, Atsusi, "Preparing the Next Generation of Instructional Designers: A Cross-Institution Faculty Collaboration" (2018). Faculty Publications. 2067. https://scholarsarchive.byu.edu/facpub/2067 
Preparing the Next Generation of Instructional Designers: A Cross-Institution Faculty

\author{
Collaboration \\ Patricia J Slagter van Tryon \\ East Carolina University \\ Jason K McDonald \\ Brigham Young University \\ Atsusi "2c" Hirumi \\ University of Central Florida
}




\begin{abstract}
The ability of novice instructional designers to become skilled problem-solvers, who select and apply appropriate instructional design (ID) models in their work environments, are key competencies generally sought after in introductory ID courses. Yet, the proliferation of ID models, coupled with varied philosophies and practices about how ID is taught may pose challenges for ID educators seeking to prepare the next generation of leaders in the field. With little empirical research or documented best practices, ID educators are left to their own judgment about to how to navigate the practical challenges that can arise in the pursuit of their teaching goals. This paper shares insights on how ID educators across institutions teach introductory ID under varied conditions, and how ID educators can support each other in addressing challenges faced by those teaching introductory ID and seeking to improve their own practice. Using action research methods, we engaged in cross-institutional collaboration, sharing teaching approaches, philosophies, modes of delivery, instructional strategies, resources, models, and products of instructional design with each other as a means to understand and improve our own teaching practices. We also developed a model for cross-institutional faculty collaboration that is immersive, cyclical, and theory-based, and provides a guide for other ID educators to collectively engage in the work of supporting each other in the common goal of preparing the next generation of instructional design leaders.
\end{abstract}

Keywords: instructional design; collaboration; model; teaching practices; action research. 
Preparing the Next Generation of Instructional Designers: A Cross-Institution Faculty

\section{Collaboration}

An instructional design (ID) model, in its most rudimentary form, is a tool for designers to logically engage in producing solutions to instructional problems. So it is no surprise that a large number of ID models have been developed, many focused on the needs of unique types of instructional situations. The plethora of models, in turn, has led to a number of schemas that categorize the approaches in many different ways to highlight their similarities, differences, or possible applications. For example, Andrews (1995) classified models by their theoretical foundations. Gustafson and Branch (2002) divided ID models into three broad categories including Classroom-Oriented, Product-Oriented, and Systems-Oriented models. Broader schemes for grouping design models have done so by their stated purpose or approach, (Edmonds, Branch, \& Mukherjee, 1994), or their intended practical application (Quinn, 1994).

However, all of these individual models and broader classifications can make it difficult for the novice designer to determine the appropriate model to use in any given situation. The simplicity of many ID models often hides the reality that in practice instructional designers are very flexible in their use of process (Yanchar, South, Williams, Allen, \& Wilson, 2010). So the design demands of particular contexts can place difficult cognitive burdens on novices to evaluate and apply various models to the specifics of the environments in which they work. In other words, the proliferation of available models may cloud, rather than facilitate, designer decision making.

It follows, then, that teaching ID may be as complex in nature as the models themselves, as experienced designers (in the role of ID educators) attempt to use the many available perspectives to support the education of novice designers. Empirical studies in how instructional 
designers use models suggests that a holistic approach should be adopted in the teaching of ID process, and not focus too strictly on any single model (Botturi, 2006; Shambaugh \& Magliaro, 2001). Yet this introduces challenges for faculty teaching ID courses, who must still make practical decisions about what model or models to cover, in what order, and in what manner. For example, rigorously assessing the characteristics of target learners and other stakeholders is a key facet of most ID processes (Dick, Carey \& Carey, 2015). However, in K-12 settings, teachers do not systematically analyze learner characteristics (Young, Reiser, \& Dick, 1998), let alone stakeholders such as administrators, other educators, or families. This is not to say K-12 teachers do not generate insights about their students' (or others') needs, just that they do so in ways very different from the procedures suggested by most ID models. So how should ID educators teach needs analysis when they may have classes comprised of students who will both teach in K-12 settings, as well as become instructional designers working in settings which rely on more traditional processes?

Additionally, literature points to expectations held by those who employ instructional designers, suggesting that graduates of ID programs should have independent problem solving skills and be able to adapt to new situations (Sugar, 2015; Winn, 1997). They may also be expected to perform functions beyond traditional ID activities, such as project management (Cox \& Osguthorpe, 2003; van Rooij, 2010). Consequently, Larson and Lockee (2009) suggested that ID programs must be flexible, and address the needs of novice designers in the varied contexts in which they will become employed, moving away from the more generalist approach found in many programs.

When we consider how such insights may impact the preparation of the next generation of instructional designers--when the complexity of problems they face is only going to increase-- 
we ask how can we better empower new IDs to be independent thinkers and highly skilled decision makers? The next generation of designers are currently novices in their design practice, yet must be poised to work in a competitive work environment with high expectations for measureable results in areas for which they have been hired. They may serve in business and industry settings, government agencies, the military, medical and allied health professions, K-12, or higher education. But regardless of where, they will need to quickly analyze needs, defend their own methods, models, and recommendations, all as they apply sound ID principles to formulate creative solutions to real-world problems. The next generation of designers must also keep abreast of how our understanding of human learning, ID, technology and workplace performance continues to evolve so they can innovate training and education, and advance theory, research and practice to help individuals remain competitive in today's ever-changing world.

The challenge is that there appears to be little empirical research about teaching instructional design or the relative effectiveness of ID models including how to help novices navigate the landscape created by the large number of existing models. ID educators are left to their own judgment and wisdom in answering the questions we pose above, as well as the numerous other issues that arise in the day-to-day preparation of new designers. But we believe that many educators are making strong judgments and developing valuable insights. So to help address the challenge, we also propose that the knowledge gained by ID educators, if shared beyond the bounds of the courses in which they teach, could be used as a source of "practical wisdom" that could strengthen other instructors' abilities to cope with the issues that arise in their own practice (Dunne, 1993, p. 280). Our purpose, then, is to explore how cross-institutional 
collaboration can help professors of ID develop new insights so they are better prepared to educate the next generation of instructional designers.

\section{Method}

To facilitate the sharing and synthesis of data across institutions, we employed a form of action research, where we as educator-researchers engaged in collaboration both to "make meaning of interpreting a particular phenomenon," as well as "to solve a practical problem" (Merriam \& Tisdell, 2016, p. 49). The phenomenon under study was how cross-institutional collaboration can help teachers of ID develop new insights. The practical problem was our interests in improving our own practice so we are better prepared to educate the next generation of instructional designers. We conducted the study using four phases of action research as described by Merriam and Tisdell: plan, act, observe, and reflect.

Our planning consisted of each researcher writing a brief case study of how he or she taught his or her own introductory ID course (Stake, 1995). Each case was written according to a common outline:

- Context, which consisted of descriptive information about the course (instructor background, delivery mode, number of students, etc.), the program in which the course is taught, and the teaching philosophy of the course instructor. This basic information was provided to help the collaborators better situate the details about each course's outcomes, strategies, assessments, and activities.

- Each course's learning outcomes and key assessments.

- The instructional strategies foundational to each course.

- The instructional resources and support that help instructors implement their strategies. 
- Challenges faced by the course's instructor or students, based on data gathered by each instructor while completing their teaching assignments.

The three cases we wrote to the common outline facilitated our cross-institution collaboration, which occurred during the act phase. By collaboration we mean multiple discussions that consisted of asking each other questions about our individual approaches to ID education, describing how our teaching apparently differed from each other and from the other cases we read, offering suggestions about how we reconcile the challenges we face with our students, curriculum, or institutional requirements, and brainstorming how the ideas described by our co-researchers might be implemented in our own courses. We also shared teaching resources, including course syllabi, textbook selections, job aids, and instructions for activities used in our own classes. We held multiple discussions through email over a period of two months, supplemented by four meetings through video conferencing software.

The last two phases helped us study our own activities to find those elements that could be useful to other ID teachers. The observe phase consisted of analyzing the record of our discussions (emails, and notes from video conferences) for patterns or insights about what we learned about cross-institution collaboration in the context of preparing new instructional designers (and by extension, the next generation of leaders in the field). Finally, the reflect phase consisted of summarizing our insights in this article and into a model for how others can conduct similar collaborations across institutions, as they seek to better prepare the next generation of students at their own institutions.

These four action research phases are reflected in what follows. First, we present our three case studies. Next, we summarize the discussions occurring during our collaboration. 
Finally, we present the observations and reflections that led to the creation of our model of crossinstitution collaboration in the context of teaching ID.

\section{Case 1}

- Course: EDTC 6020 Principles of Instructional Design.

- Instructor: Masked, Associate Professor, Instructional Technology, Department of Mathematics, Science and Instructional Technology Education, "University Case 1."

- Experience: 9 years as an instructional designer, 3 years teaching introductory ID.

- Delivery: $100 \%$ online asynchronous, Fall/Spring Semesters 15 weeks \& 5 Week Summer Intensive.

- Primary Text: Brown and Green (2016) The Essentials of Instructional Design Connecting Fundamental Principles with Process and Practice. Supplemental readings in ID, learning theory, and practical experience with the design of instruction within realtime learning environments, interactions with SME, and development of instructional resources.

- Students: 25-50 each semester, graduate students in the MAEd and MS in IT programs with students representing, nursing and allied health professions, business, theater, hospitality, economics, and various majors in education.

The Instructional Technology (IT) program at University Case 1 (University Case 1) is located in a rural area with an over-all enrollment of 28,000 . The university offers two degree programs, a MAEd and a MS in IT. The IT program also offers three certificate programs; Computer-based Instruction, Distance Learning and Administration, and Special Endorsement in Computer Education. In response to student feedback, and to reach a greater number of in State candidates and beyond, the College of Education (COE) at University Case 1 supported the IT 
Program in moving from a face-to-face program to $100 \%$ online delivery and is currently in its $12^{\text {th }}$ year in this configuration. This university-wide forward thinking has been quite fruitful resulting in significant growth of the IT program.

The IT Masters programs and certificate programs steadily maintain a graduate student population of 160 with approximately 20 graduates per academic year. Graduate students seeking the MAEd in IT come from many backgrounds as we enroll many students looking to change or enhance career opportunities. Students represent such fields as, nursing and allied health professions, business and industry, theater, hospitality, economics and the military. Students in the MS in IT program seek to hone their expertise in the design of instruction to work within or remain in business and industry, higher education, the military, medical and allied health professions, various government organizations, as well as the non-profit sector. The IT program has 7 full time faculty; two are full professors, three associate, one tenure track, and one full time teaching assistant professor. Where needed, a small group of adjunct professors support the program.

Within each program, ID is presented throughout each course with two courses specifically focused on the ID process. The introductory course, EDTC 6020 Principles of Instructional Design, is designed to immerse graduate students in the systematic ID process and while this course includes the full scope of the design process, there is particular focus on task analysis, learner and context analysis, interactive development and the practical application of instructional strategies. EDTC 6020 is a prerequisite for the second course in sequence, EDTC 6025 Analysis and Evaluation in IT. In EDTC 6020, students complete a series of assignments, discussions, and projects each within a particular facet of the design process that supports their final development of an individual ID document addressing an educational problem that each has 
identified. This ID project is a designated artifact project that is to be completed, refined, and uploaded to a professional electronic portfolio.

My personal philosophy of teaching is an amalgam of my social constructivist and action oriented worldview and my belief in one's social responsibility for the well-being of others. I believe education is at its best when student-centered engagement occurs both within as well as beyond classroom walls where it has the opportunity to be consistently embedded in authentic experiences through the multiple perspectives, respect, and dignity of all cultures. I seek to provide each learner with a learning context that builds confidence in decision making where one can offer a rational and informed defense for his or her response in a problem solving event. Through my research I have discovered that social context matters in a teaching and learning environment as does a sense of the group and each individual's important position within it (Slagter van Tryon \& Bishop, 2009).

\section{Targeted Outcomes and Assessments}

The IT program seeks to develop leaders in ID that have expert reasoning and decision making ability and are highly skilled problem solvers. With this in mind, the course design is purposeful in not placing too much emphasis on one particular design model but rather to explore a wide range of models and practical application in varied settings (Brown \& Green 2016). The focus is learner-centered with intentional engagement with students in a design process that is situational and relevant for them as individual yet collaborative theorists and practitioners (Lave \& Wenger 1991). Much consideration is given to the $100 \%$ online context where often times social cues for interactions are not as prevalent as in face-to-face courses therefore the course is highly interactive, instructor-led, and purposefully paced (Slagter van Tryon \& Bishop, 2006). Students interact regularly in exploring ID and evaluation models and 
are asked to offer reasoned critique of the processes. The course is supported by the following objectives: Given an instructor supported and real time instructional context, students in EDTC 6020 will:

1. Describe the major components of the ID process.

2. Defend selection decisions for ID models in addressing an educational problem.

3. Describe how learner characteristics and entry behaviors can be identified for a specific population.

4. Conduct a real-time task analysis with support of an SME.

5. Formulate measurable performance objectives from instructional goals.

6. Develop objective-referenced assessment items tightly aligned to performance objectives.

7. Suggest motivational activities for a specific instructional task.

When students are able to successfully defend their selection and application of an ID model or a blend thereof as per the aligned rubric, and similarly to identify and apply appropriate evaluation models within their own learning environment, each has demonstrated preparedness to implement their design albeit on a small scale. Each student is considered successful in the design process when each demonstrates implementation of their design in a real-time learning environment according to course rubrics.

Outcomes support the next generation of instructional designers in preparing each to begin to decipher the messy and non-linear design processes found in the role of the instructional designer in any field. Students gain confidence through this experience such that when faced with a real world ID project, it is not their first time tackling such an endeavor in responding to its challenges operationally, socially, and programmatically. 


\section{Instructional Strategies}

Collectively, each iteration of the course maintains a social cognitive and constructivist approach. All facets of the design process are embedded in practical authentic experiences. When studying front end analysis, for example, each is expected to conduct a needs assessment and learner analysis within their own learning context and similarly, when progressing into task analysis students must engage with a SME and report all interactions therein. All design must be implemented and evaluated in a real time context. This authentic learning approach offers the opportunity to hone decision making skills and to reflect on those skills as each is asked to defend their selection and application with support from course content and ID models presented. To be immersed in the ID process in this way creates meaningful and relevant experiences that better prepare graduates for the real world of work. Students analyze the educational context, collaborate publically with peers and experts, then begin to formulate their potential solutions to educational problems. While group activities are prevalent, grading is individual where each has the opportunity to demonstrate mastery. Individual responsibility and accountability to the larger group are skills sought after by employers.

\section{Instructional Resources and Support}

ID courses are facilitated by the learning management system (LMS) Blackboard. Multiple opportunities to interact with new concepts are present and offer both peer feedback as well as instructor feedback in the process. Course supports are consistently integrated such as relevant literature, discussions, screencasts, diagrams, sample (model) assignments, and various software for generating visual aids. Each course includes a firm course schedule to maintain pace, clearly stated course goals and objectives, and facilitates an interactive approach through chats, discussion boards, blogs, wikis, announcements, audio, video, and where appropriate 
synchronous two-way audio and video interactions for just-in-time support (see sample resources at Masked)

Students with a high self-motivation for learning and willing to take risks seem to perform best. These students tend to utilize the wide range of available supports, asking relevant questions while selectively integrating those course supports in their own work. The course entails a refined reflection process and it has become clear that students taking time to focus intently on reflection and refinement experience a more positive transition into becoming skilled instructional designers. While the practical experience supports the application of design principles in students' real-time world of work, it also supports the building of content knowledge in the language of ID and being confident in it. We work to have each student realize the theory of ID through their own Socratic questioning and reflection with the immediate practical application of those principles.

\section{Challenges}

The design process is not an easy task for students to grasp initially and it falls to the course instructor to maintain consistent engagement and just-in-time support. Yet, even with a high level of engagement and successful student outcomes, challenges remain. Among the challenges, the varied fields represented is perhaps most prevalent. Practicing teachers will consistently refer to lack of time and resources for design and very limited opportunities for collaboration among peers. Teachers in most cases are not required to move beyond basic formats of lesson plans to be reviewed by administrators and while teachers support the merits of well-designed instruction, most will report limited opportunity to experience the ID process at their respective schools in the same way as in their design courses. Further, teachers often report that administrators are expecting competencies in repairing technology as a result of the study of 
design; another challenge posed in common misconceptions of the field. Military students have work environments that pose challenges as well and while they are well supported in the full application of ID, as students, often note highly classified content and work environments limiting the sharing of information. Oftentimes the development of instruction must be either redacted or fictionalized to be submitted as coursework which somewhat degrades the practical experience and collaborative processes. For students in nursing and allied health professions, although critical thinking and problem solving skills are evident, there is often a lack of general knowledge of learning theory and practical application of instruction in general. Much prerequisite work is needed in support of success for these students.

To overcome the challenge of varied fields, students are encouraged to offer a detailed narrative of their current or intended work environment where collectively, suggestions are shared with classmates to help address actual or perceived limits at work. As instructors, we engage with the group and individually with students to address actual and perceived limitations in the workplace. Through these interactions we work to prepare students for the varied work place cultures they will experience as we stress the importance of interpersonal and communication skills for successful interactions. We get to know the work environment as instructors and offer our own skills in design to address particular roadblocks each may encounter. The ID course is therefore a constant conversation over students' experiences and challenges considered in every iteration of the course.

\section{Case 2}

- Course: IP\&T 564, Introduction to Instructional Design.

- Instructor: Masked, PhD, Associate Professor, Department of Instructional Psychology \& Technology, "University Case 2." 
- Experience: 17 years as a practicing instructional designer and administrator/executive and 2 years as a teacher of introductory ID.

- Delivery: Totally Face-to-Face, 15 weeks each Fall Semester (September - December).

- Primary Text: Dirkson (2016) and Gibbons (2013), with supplemental readings on client/SME interactions, assessing instructional situations, generating instructional strategies, prototyping and the testing/evaluation of prototypes, and pitching ideas/strategies to clients.

- Students: 15-18 each semester, primarily graduate students from the IP\&T program, but also frequently taken by graduate students in other programs seeking elective credit, or by undergraduates exploring the ID industry.

The department of Instructional Psychology \& Technology (IP\&T) is housed in University Case 2's School of Education, and employs ten full-time, tenure track faculty, supplemented by $2-5$ adjunct faculty. About 80 students are enrolled in the department at any given time. University Case 2 is a research university in an urban setting, enrolling about 30,000 undergraduate and 3,000 graduate students. IP\&T offers two degrees — an MS and a PhD. Both programs are on-campus and fully face-to-face; currently the university administration has not approved any graduate programs to be taught online. Students admitted to the program can specialize in one of four areas: instructional design/development; evaluation; assessment/measurement; and research. All specialties are highly project-focused; in each, students are required to complete at least one culminating project demonstrating their skills in the emphasis, such as a significant instructional development project for a client, or an evaluation of a large program. This reflects the teaching philosophies of most of the faculty in the department, 
who are oriented towards situated learning approaches and helping students join professional communities of practice (Wenger, 1998).

Most IP\&T students complete the instructional design/development specialty. The backgrounds of students who complete this specialty are very diverse. About one third come to the program immediately following their undergraduate work, often from a field like psychology. Others are existing professionals either pursuing a career change, or seeking a credential for an ID position they came to by assignment. Some students begin the program with prior experience as K-12 teachers, but most do not return to the classroom after completing their degree.

Most graduates of the instructional design/development specialty accept employment in the local educational technology industry, or continue employment they held previous to their graduate studies. Common careers include: in-house instructional designers developing online training modules; designers with organizations developing informal learning systems, such as museum education or instructional films; or as employees of the university's distance education division or teaching/learning center. In contrast to other cases discussed in this paper, few University Case 2 graduates pursue careers in the military or healthcare.

IP\&T's introductory ID course is labeled IP\&T 564. It meets in a single, three-hour block once a week, and is meant for students to take during their first semester in the program. Most students are enrolled in the IP\&T department; however, each semester the course also enrolls 2-3 students from other majors. Students in the ID specialty are taking the course to prepare for work as a professional instructional designer. Students from other specialties may not be interested in ID as their profession, but they are interested in the field broadly and are usually pursuing related career paths. Those from other programs are usually undergraduate students exploring graduate work in ID, or graduate students from other educational programs filling an elective credit. 


\section{Targeted Outcomes and Assessments}

The primary outcome of IP\&T's instructional design/development specialty is to prepare students for professional work in the ID industry. This influences the content, instructional strategies, and assignments in all courses, especially IP\&T 564, which has the primary outcome of students individually completing an online instructional module for a client of their choosing. The specific learning outcomes that support this primary outcome are:

- Identify the scope of the ID industry;

- Assess instructional situations by investigating learner and stakeholder needs/desires, and by evaluating the design context;

- Define ID challenges, including desired changes in the learner population;

- Generate possible approaches to instruction, that could address identified challenges and goals;

- Create prototypes of ID solutions that communicate your intentions to others, and that allow your ideas to be evaluated;

- Demonstrate an emerging design character.

These outcomes are assessed through rubrics focused on identifying key attributes of an effective project. Rubrics follow a consistent format, with criteria to be evaluated grouped under the heading, "To what extent does the project exemplify the following characteristics?" Each criterion can be marked as Exemplary; Somewhat; or Not at All. Points are awarded at each level depending on the contribution a criterion makes towards the overall project success. A sample syllabus and example rubrics can be found at (Masked). 


\section{Instructional Strategies}

IP\&T 564 is integrated into the department's design studio curriculum (Gibbons, 2016; Rich, West, \& Warr, 2015). The design studio is a form of project-based learning in which students work for extended periods of time on authentic design problems, under the direction of instructors who typically do not lecture but who model design skills and offer intense feedback on students' work. For detailed reviews of the design studio approach, including how it can be used in ID, see Cennamo (2016), Clinton and Rieber (2010), and Schön (1985).

Consistent with the design studio philosophy, early in each semester students are given a challenge that will allow them to practice design skills as applied to an educational problem. While the specific wording of the challenge varies somewhat from semester to semester, the essential assignment for students is to find a client who will sponsor the development of an online module that teaches a skill to a set of learners. Once students choose their client most remaining class time is dedicated to project work (typically starting in Week 7 or 8 of the 15week semester). The instructor, sometimes assisted by students from the Advanced ID course, offers feedback to students either individually or in small groups, providing individualized instruction on how to address the next phase(s) of their design process, or providing encouragement to cope with challenging situations they face. At the end of the semester students present their work (a prototype of their product) to the rest of the class for final feedback, and then deliver their prototype to their client.

Additionally, IP\&T 564 is integrated with the introductory course in instructional media production (IP\&T 560) and introduction to evaluation (IP\&T 661). In this context, integrated means that assignments completed in one course become prerequisite work for assignments in the other courses. For example, in IP\&T 564 students create low-fidelity prototypes of 
instructional artifacts, which they develop into working products in IP\&T 560. The instructors also support each other in teaching various topics and skills at whatever point and in whatever course makes the most sense, and not within the confines of the course to which they are formally assigned.

The experiential outcomes of IP\&T 564 and the design studio strategy have been developed to support students who are growing into the next generation of ID leaders. Surveys with those who employ IP\&T students indicate that the advantage offered by their graduate training is that students begin employment knowing how to blend a theoretical approach to ID that relies on rigorous learning and instructional theory, with the practical realities of solving problems in fast-paced environments, where people often have less information than they desire. This is an outgrowth of the assignments that students complete in their design studio training, and is typically seen as one of the strengths of the studio approach (Salama, 1995).

\section{Instructional Resources and Support}

The textbooks currently used in IP\&T 564 are Dirksen (2016) and Gibbons (2013). Dirksen is a practitioner-oriented text on developing eLearning, and provides students with clear and engaging examples of how ID skills realistically apply in concrete situations. Gibbons' text examines architectural ID theory. Using the textbooks together helps students integrate both the academic and practical aspects of ID, and avoids the shortcomings of focusing exclusively on either pragmatic processes or the philosophical and theoretical foundations of the field. The textbooks are supplemented by readings that address individual skills more completely or from different perspectives.

The design studio approach of IP\&T 564 is supported by various in-class and out-of-class experiential learning activities, especially early in the semester before students have chosen their 
culminating project. For example, in-class experiential challenges are used to introduce the knowledge base of ID while avoiding as much as possible lecture as an instructional activity. One activity students typically enjoy is the introduction to learner analysis. During the first five minutes of class, students are divided into groups of three, and sent across campus with instructions to engage with the campus population in various locations. At least one group is assigned to observe a large lecture class; other groups observe in the library; other groups interview a few students in the cafeteria about their university experiences. After students return to class they debrief with the instructor, who uses their experiences to discuss the role of analysis in a project. This experience primes students for a discussion with their instructor of what skills could help them complete similar analysis activities effectively in the future. After class, they then study analysis further through textbook readings.

University Case 2 hosts its own, proprietary LMS called Learning Suite, which is used to store and deliver course materials to students. This typically means students refer to the LMS for the syllabus and course schedule, to access supplementary course readings, to download copies of handouts and assignment rubrics, submit assignments, and review their grades. Occasional announcements are also posted in the LMS. Lists of supplementary readings, along with handouts, templates, and rubrics to support assignments, can be found at (http://jkmcdonald.com/teaching/introduction-to-instructional-design/).

\section{Challenges}

Although this approach to teaching IP\&T 564 works well for students in the instructional design/development specialty, it can be difficult for students in other specialties, and even more so for students from other programs. Some of their challenges are logistical. For example, student enrolling in IP\&T 564 as an elective for another program do not participate in the rest of 
the design studio sequence, and so some adjustments need to be made so they can be successful without completing assignments in the complementary courses.

But other challenges are more fundamental to the course strategy. The studio-based and project-based design of IP\&T 564 assumes that students are interested in actual careers as instructional designers. This is a safe assumption to make for students in the ID specialty. Even if they do not enter careers exactly aligned with projects they completed in IP\&T 564, they usually find their experiences transferable enough that the course still helps them to be successful in their later work. But students with other backgrounds and interests typically also have different expectations for the outcomes they will achieve in the course. This is usually addressed by the instructor in the first week of the semester, explaining the course purpose is primarily to prepare professional instructional designers, and asking students with other interests to take responsibility for extracting whatever other value they are looking for. Essentially, students are asked to "play along" for the course of the semester, assuming the role of an instructional designer in-training while they are in the class. Instructors also try to help students with other purposes shape their culminating course project to align with their interests. While some students without career interests in ID struggle with the nature of the course, most eventually understand how to work in the manner asked of them and usually exceed their own expectations by the time the reach the end of the course.

\section{Case 3}

- Course: EME 6613 Instructional Systems Design

- Instructor: Atsusi Hirumi, PhD, Professor, Instructional Design \& Technology, University of Central Florida

- Experience: 24 years teaching basic ID, 27 years as an instructional designer 
- Delivery: Totally online W(eb) and M(ixed) mode, 15 weeks fall and spring terms

- Primary Text: Dick, Carey, and Carey (2015)

- Students: 30-40 Fall, 20-25 Spring. Graduate students primarily in ID\&T, but also in Modeling and Simulation, Nursing, and Digital Media.

The Instructional Design \& Technology (ID\&T) program at the University of Central Florida (UCF) consists of four full-time tenure track faculty and a team of three-five adjuncts. Our mission is to optimize human performance through research and the development of innovative, high quality training and educational programs. Programs of study include four professional certificates, three master's degree tracks, and two doctoral programs as listed in Table 1.

Table 1

Certificates and degrees offered by the ID\&T program at UCF Professional Certificates MA Degree Tracks Moctoral Degrees

- Instructional Design

- Instructional Design of Simulations and Games

- Educational Technology

- e-Learning
- Instructional Systems

Design

- Educational Technology

- e-Learning
- $\mathrm{PhD}$ in Education

- EdD in Education

The two design certificates and MA track prepare graduates to work in business and industry (B\&I) as instructional designers and training specialists. Educational technology teaches educators to integrate emerging technologies in K-12 and higher education, and e-Learning 
prepares both educators as well as instructional designers to design and deliver online and hybrid coursework. Graduates of the doctoral programs seek opportunities across higher education, B\&I, and government agencies as educators, researchers, training managers, and center directors. A significant percentage of our students are K-12 and postsecondary educators who are looking to enhance their technology skills and knowledge, or move into careers as instructional designers. Others come from varied disciplines with common interests in training and ID. A smaller, each significant number are practicing instructional designers returning to school to receive formal education and degree in the field.

All courses are offered totally online and in mixed mode to meet the needs of working professionals. With all branches of military, an exceptional hospitality industry, growing medical presence, and high tech corridor, Central Florida also boasts an exceptional high number of working professionals in ID and related fields of interest that provide faculty, staff, and students with an array of research and development opportunities that distinguish ID\&T at UCF.

Two integrated core courses provide students with a basic introduction to the overall systematic design process: EME 6613 focuses on analysis and design, and EME 6226 focuses on development, and formative and summative evaluation. A third core course, EME 6507 Multimedia for Training and Education, also covers basic multimedia production skills but is not purposefully integrated with either EME 6613 or EME 6226.

EME 6613 Instructional Systems Design is the fundamental design course depicted in this case that is taken by all graduate students in the ID\&T master's degree program, and is required in three of four graduate certificates offered by the program. EME 6613 is also a required pre-requisite for students in the $\mathrm{PhD}$ and $\mathrm{EdD}$ in Education. Approximately twenty to twenty-five graduate students from the ID\&T program, and another fifteen to twenty from other 
graduate programs across UCF (such as the Modeling and Simulation, and Nursing) register for EME 6613 during the fall, and approximately twenty to twenty-five with a similar ratio of program students take the course during the spring term.

Personally, I believe in experiential learning. After 15+ years of compiling, analyzing, and developing a framework for applying alternative instructional strategies (Hirumi, 2014a, 2014b, 2013, 2002a, 2002b), I've come to believe that children, adolescents, and adults often learn best when they are presented with authentic challenges, and skill development and the learning of facts, concepts and rules occur within the context of how they are used (Hirumi et al., 2017). Although I do use alternative strategies in other courses, I believe experience is particularly important for learning how to work with subject matter experts (SMEs) to design training and educational programs, and thus, apply Clark's (2004) model for guided experiential learning and Lindsey and Berger's (2009) principles of experiential learning to guide the design and sequencing of key instructional events in EME 6613. The basic design of EME 6613 is further delineated by describing targeted outcomes, assessments, instructional strategy, and resources.

\section{Targeted Outcomes and Assessments}

The goal for EME 6613 is to give students experience in working in teams with assigned subject matter experts (SMEs) to systematically design a unit of hybrid instruction. Teamwork and collaboration with SMEs are specified as essential interpersonal skills for instructional designers. Hybrid instruction is prescribed to give students experience in flowcharting and storyboarding (the online portions of the unit) and in designing instructor guides (for facilitating both the online and face-to-face portions of the unit). Five terminal objectives are specified to achieve the goal. Given an instructional situation and access to SMEs, learners are to: 
1. Analyze the instructional goal, learners, and context;

2. Formulate an instructional treatment plan that specifies the instructional goals and objectives, strategies, and assessment methods for a unit of hybrid instruction;

3. Create flowcharts and storyboards for the online components of the instructional unit;

4. Generate an instructor's guide for facilitating both the online and face-to-face components of the instructional unit; and

5. Demonstrate effective interpersonal skills and communications.

Achievement of the terminal objectives is evaluated using analytic assessment rubrics and teamwork evaluations. The rubrics are also used as an integral part of learning. If students post a draft one week prior to the specified due date, they are guaranteed feedback and given the opportunity to revise and resubmit before the assignment is graded.

\section{Instructional Strategies}

Clark's (2004) Guided Experiential Learning model guides the design and sequencing of instructional events in EME 6613. Each unit, presents students with (a) goals, (b) reasons and activation, (c) demonstration, (d) application, (e) integration, and (f) assessment. Guided Experiential Learning (GEL) is used for two primary reasons; experience is essential for developing expertise in design, and GEL specifies the demonstration of skills as an essential instructional event. The value of experience is discussed earlier. The importance of demonstration is supported by cognitive neuroscience research into human imagination and learning.

Imagination is defined as the ability to form mental images, sensations and concepts when not perceived through senses, and is posited as an essential dimension of experiential learning (Hirumi et al., 2017, in press; Atkinson \& Hirumi, 2010). In short, people constantly 
recall images of task performance to guide their behavior (Borkin et al., 2013), and use emulations of cause and effect relationships to guide decision making (Colder, 2011). GEL is applied to facilitate the achievement of course objectives because it explicitly addresses learners' need to "see" the application of ID tasks. Service learning, in turn, facilitates application and integration as posited by GEL.

One of the most important and difficult design skills to teach is how to communicate and work effectively with clients and subject matter experts (SMEs). Ten years ago, the development of such interpersonal skills was left to internships and assistantships offered toward the end of a student's program of study. However, based on input received from employers and onsite internship mentors, EME 6613 was transformed into a service learning (SL) course to give students additional experience working with "real" clients and SMEs.

Throughout the course, SL partners meet with teams of students on a regular basis. Specifically, SL partners meet with students at least four times: Once at the beginning of the term to establish rapport; review the instructional goal; obtain content information; determine method for gaining additional content, learner and context information; and clarify communications and expectations; and three times during the term to review and either approve or gain input necessary to finalize the analysis report, treatment plan, and flowcharts, storyboards and instructor guides.

\section{Instructional Resources and Support}

A learning management system (LMS) facilitates the delivery of the online and hybrid sections of the course. Online course materials include a course syllabus, unit overviews, supplemental information, multiple choice quizzes, assignment descriptions and assessment rubrics. Additional LMS features used throughout the course include announcements, 
discussions, conferencing, gradebook, and collaboration tools. Supplemental information reviews and builds on key concepts presented in the textbook, and three resources enhance students' design experience, including, illustrated examples of three types of goal analyses, an array of instructional strategies, and the use of animations to illustrate the completion of each basic design task.

Goal analyses. In EME 6613, students learn to complete a goal analysis to define the number and nature of instructional units to be included in a course or training program. In addition to the step-wise and content-oriented methods covered in the textbook, a whole-task method posited by van Merrienboer, Clark, and de Crook (2002) is addressed to enhance students' goal analysis capabilities. As a foundational course that is prerequisite to other courses (such as EME 6614 Instructional Game Design and EME 6601 Instructional Simulation Design), EME 6613 incorporates whole-task goal analysis because it facilitates the design of educational (and serious) games by delineating simple-to-complex examples of the whole-task that, in turn, may be used to distinguish simple to complex game/simulation levels.

Compilation of instructional strategies. Dick, Carey, and Carey (2015) present learners with one instructional strategy for designing an instructional unit that includes pre-instructional, instructional, and post instructional activities that are associated with Gagné's (1987) nine events of instruction. To enhance students' ability to design alternative learning environments, EME 6613 features over 32 instructional strategies grouped into learner-centered, teacher-directed, and neurobiological approaches to teaching and learning. Students are given outlines of the strategies along with more detailed descriptions of each strategy, as illustrated and delineated by Hirumi (2014a; 2014b). 
Animated design tasks. In addition to the narrative descriptions and static examples that may be found in the course textbook, animations are being developed to demonstrate (ID) task performance, as prescribed by the GEL instructional strategy. Audio accompanies the animation that describe the instructional designer's thoughts, actions and decisions. Testing also suggests that the animations should be divided into short segments with a menu that allows students to access the animations in random order.

\section{Challenges}

Three primary challenges to course design and delivery are faced each term (a) addressing the varied needs and interests of students taking the course, (b) preparing both students and SMEs for SL project, and (c) teamwork evaluations.

Addressing varied interests. The students seeking careers as instructional designers typically do not have problems with specified course objectives and assignments. However, educators with defined curriculum standards, and limited time and resources for curriculum development don't always see the relevance of conducting goal, subordinate skill, learner and context analyses, and designing flowcharts, storyboards, and instructor guides. To overcome such challenges, it is reasoned that students who take the course may pursue opportunities as instructional designers in business and industry, and students who pass the course have relevant ID skills and knowledge. In accordance with GEL, reasons for completing each design task are also covered at the beginning of each unit. The interest generated from working with SL partners also tends to motivate students and improve satisfaction.

Facilitating service-learning. To facilitate SL, it typically takes two-three meetings with SL partners prior to the beginning of the term, along with constant communications throughout the course. Time requirements and the nature and quality of deliverables must be considered. It is 
also useful to go through the goal and subordinate skills analysis processes with assigned SMEs first, to facilitate later interactions between SMEs and students. Time must also be allocated to mentor students on how to interact with clients and different types of SMEs. Supplemental materials, along with prescribed protocols for contacting, scheduling, and facilitating meetings with SMEs are posted in conjunction with the primary course assignments.

Evaluating teamwork. Teamwork is viewed as important aspect of the field and is a fundamental component of the course. After being instructed to establish communication protocols, schedule regular meetings, and establish team norms and expectations, teamwork seems to go well in the majority of cases. Valid and reliable assessments of teamwork, however, continue to be elusive. Even though individual assessments are keep confidential, students believe less than optimal scores may lead to negative repercussions. Students also inflate teamwork scores to earn higher grades. Recently, students' teamwork was evaluated based on the meaningfulness of the feedback given to their teammates rather than their contributions to teamwork as evaluated by their teammates. Assessing the feedback has led to what appears to be more valid and meaningful comments but teamwork evaluations remain a major challenge.

\section{Discussion}

After individually preparing the above cases, we engaged in the cross-institution collaboration as described in our Method section. We found a number of similarities and differences in course design, delivery, and content across the three cases. In the following discussion, we review what we learned as we collaborated together about our own teaching. We then describe how we synthesized our discussions into a proposed model for facilitating collaboration among educators who teach introductory ID courses. 


\section{Similarities Across Cases}

Perhaps the most obvious finding from our discussions was the similarities across our cases. In particular, all three introductory design courses: (a) serve as prerequisite to, and are purposefully integrated with other courses offered by each program; (b) focus on the application of design skills in an authentic context; and (c) face challenges reconciling differences in students' needs and interests. Among the unique value of some similarities (discussed below), learning about the similarities in each other's approaches highlighted places where we could profitably share resources to improve the practices in our own courses.

Integrated coursework. In all three cases, the introductory design course serves as a prerequisite to, and is purposefully integrated with other courses offered by each program, and it is through such integration that the key components of a systematic design process, including analysis, design, development, and evaluation, are addressed. In general, each introductory course provides students with an initial experience in instructional analysis and design. Ensuing and concurrent courses utilize design documents and artifacts generated in the introductory course as a foundation for further training in development and evaluation. The use of assignments across courses was a valuable similarity to discover, since some of the challenges we face in our teaching surrounded issues of courses integration. Discovering all three of us followed an integrated course model allowed us to share ideas based on our own experience about how our collaborators might address their challenges.

Focus on application in an authentic context. All three courses include design projects that require students to apply systematic design skills in authentic contexts. This includes having students engage with real clients or SMEs during at least some phases of the course projects. The design projects also include students creating some kind of ID artifact that is expected to meet 
the approval of a client. Although the specific teaching approach is named and applied in somewhat different manner across the three ID courses, as discussed later under key differences, it is apparent that they all still focus on the application of skills, rather than only the acquisition of knowledge, and real-time interactions with clients and SMEs are thought to be essential components of students' preparation and experience. Because our course activities were designed in support of skills development in authentic context, discussion of our approaches to learning stimulated our interest in adopting some of the resources developed by our collaborators.

Reconciling competing demands. In all three cases, the introductory design course is taken by students from different disciplines with different needs and interests. As a result, we all felt that we had to modify requirements and manage expectations so students can learn what will be most valuable for them in the future. For example, many K-12 teachers and students in professions such as nursing begin their design process with explicit national and/or state standards. As a result, they require different analysis skills and knowledge than others who may have to define their own learning and performance outcomes. Some students may see little relevance in learning skills that are most applicable when designing interactive, technologybased instruction, such as creating flowcharts or storyboards, when they may solely be working in face-to-face learning environments. The value of discussing competing student demands was twofold: first, we received moral support as well as useful validation that the struggles we face are not unique to us as teachers or to our institutions. Second, we shared ideas about how we could better situate learning activities in authentic challenges that would help students develop ID skills, knowledge, and dispositions within real-world contexts, while also allowing them to tailor those skills to the needs of the environments in which they would later work. 


\section{Differences Across Cases}

Our discussion also revealed a number of differences across cases, specifically in (a) course delivery, (b) the design of course activities, and (c) instructional resources including textbooks. Discussing these differences provided a different type of value to our collaboration than did discussing similarities, namely, understanding each other's approaches and points of view provided us opportunities to reflect on the rationale that undergirded own practices, and, in some cases, inspired us with ideas to experiment with in our own courses.

Differences in course delivery. Each introductory courses is delivered through different modes. In one design course, like all other courses offered by the program at that university, is offered $100 \%$ online to reach a greater number of candidates across the state and beyond. In contrast, the course in Case 2 is delivered in conventional face-to-face fashion, meeting in-class in a single, three-hour block once a week like all other graduate courses at that university. In the third case, the design course is delivered in both totally online and hybrid fashion because a significant number of students continue to express preferences from some face-to-face meetings, and to enable foreign students, who are limited in their ability to take online courses due to federal law, to take the course and earn their degree. As we discussed these differences, it became apparent that comparing the different mode of course delivery was not a matter of curiosity, but it meaningfully affected our individual course strategies. For example, the studio model in Case 2 is greatly facilitated by having all students on-campus, where they can not only meet together frequently, but also can serendipitously find themselves "bumping into each other" as they enter or leave the studio, which facilitates their ability to share ideas with each other at unexpected times and in unexpected ways. In contrast, the totally online and hybrid courses necessitated further planning and integration of both synchronous and asynchronous 
telecommunication technologies, such as but not limited to webconferencing, online discussion forums, and wikis, to facilitate teamwork and the interchange of ideas.

Differences in course design. Although in all three cases students engage in authentic design projects, there is difference across institutions in the specific assignments and activities with which students are tasked, and the instructors follow somewhat different learner-centered approaches based on their educational philosophy and experiences.

In the first case, students are allowed to select and apply the ID model that they believe best suits their needs, and, following a social constructivist paradigm, have to rigorously defend their choices as a means to hone their decision-making skills. Students conduct a task analysis with support from an SME, formulate objectives and assessments for a variety of conditions, including online, blended and conventional face-to-face (F2F) learning environments, and suggest motivational activities to facilitate learning during specified instructional events.

In the second case, the instructor also focuses on independent decision-making, applying a studio approach that promotes students working on their own. Once students choose a client and a project, most of class time from that point forward is dedicated to project work, including generating multiple possibilities of instructional approaches and creating prototypes of ID solutions, with the culminating assessment being a prototype of an online instructional unit. Few lectures are offered by the instructor. Rather, the instructor and students from an advanced ID course provide feedback, but ultimately provide little prescription on either the process students should follow or form their product should take.

In the third case, the instructor facilitates guided experiential learning, following the Dick, Carey, and Carey (2015) ID model (with notable enhancements) to meet the needs of local industry who are familiar with and subscribe to such methods. Students work with a client and 
assigned SMEs throughout the entire term to complete goal, subordinate skills, learner and context analyses; define objectives, assessments, and instructional strategy, generate flowcharts and storyboards, and develop instructor guides based on guided learning experiences. During the first two weeks, students form and norm teams, and select a service-learning project. Students are then given direct instruction and practice specific design tasks as they work through authentic design challenges offered by each service-learning project.

While recognizing that course strategies cannot easily be lifted from one situation and inserted into another, understanding each other's course design did provide ideas of how we could modify our individual courses to take advantage of what other's have learned about effectively teaching ID. For example, during our discussions two of the authors began brainstorming how they could require students to defend their choice of ID model, as found in Case 1. The emphasis on service learning in Case 3 was also of interest to the other two authors, both of whom also began brainstorming how to integrate this approach into their courses.

Differences in course resources. All three basic design courses utilize different textbooks and resources, reflecting variations in the courses' designs and instructional approaches. In the first case, the instructor uses, The Essentials of Instructional Design Connecting Fundamental Principles with Process and Practice by Brown and Green (2016), along with screencasts, diagrams, sample (model) assignments, and various software for generating visual aids. In the second case, the instructor uses both Design for How People Learn (Dirksen, 2016), and An Architectural Approach to Instructional Design (Gibbons, 2013) to address both practical and theoretical aspects of ID, along with articles and chapters from other textbooks that address individual skills more completely or from a different perspective. In the third case, the instructor uses specific chapters from the Dick, Carey, and Carey (2015) textbook, 
The Systematic Design of Instruction, and supplemental units on goal analysis, instructional strategies, flowcharting and storyboarding, and the development of instructor guides with animations, journal articles, and handouts generated or gathered over time. Discussing why and how we used these different resources led to additional reflection on the part of each author about our rationales for the instructional choices we make; this in turn led to reflection about how we might be able to improve our own approaches through the insights we learned from our collaborators.

\section{Preparing the Next Generation}

A model for informing future dialog. Our discussion of similarities and differences across cases led us back to our research question about how cross-institution collaboration can help ID educators better prepare the next generation of instructional designers. Throughout our discussions we discovered we were each learning new strategies or activities that would be beneficial to our own students that we plan to implement in our courses. Additionally, as we explained, and sometimes defended, our individual approaches to each other, we also found ourselves reflecting on our own practices and what we value as professors of ID. This led us to be more thoughtful about why we engage in the activities we do, and how to justify them using our knowledge of ID, learning and instructional theory.

We believe what we learned from our experiences will be valuable to readers who also teach ID, and who are interested in improving their own practice through similar cycles of dialog and reflection with their colleagues. So based on our experience we propose a model for how faculty can collaborate across institutions as they collectively engage in the work of preparing the next generation of instructional designers. We emphasize that this is not a new model for teaching ID, but a model to facilitate collaboration between teachers of ID who are interested in 
learning from each other. We organize our model using Lindsey and Berger's (2009) three universal principles of experiential learning. Their work became a useful framework to describe our collaboration as we came to recognize that our efforts were in actuality an instance of our own experiential learning, since the discussion, cooperation and reflection in which we engaged for this project is central to authentic forms of the course design experience. The principles articulated by Lindsey and Berger are:

- Framing the Experience - Experiential learning begins as one communicates the instructional objectives, assessment criteria, expected behaviors, and social structure (with peers, instructors, and the environment beyond the class) of the learning experience.

- Activating Experience - Learners engage in authentic experiences that: (a) facilitate transfer; (b) allow for decisions that have authentic outcomes; (c) orient learners to how and why the experience is relevant for learning; and (d) are at an optimal level difficulty to challenge learners, but not so difficult that they do not have a reasonable expectation for success.

- Reflecting on Experience - Experiences must be analyzed for one to learn from them. Reflection should involve learners answering the questions, "What happened?" "Why did it happen?" "What did I learn?" and "How would I apply this knowledge to future experiences?"

Using these principles, we derived an iterative model consisting of three cyclical phases, with three steps within in phase depicted in Figure 1. 


\section{FIGURE 1 GOES ABOUT HERE}

- Phase 1: Engage in initial collaboration to understand each other's teaching context, philosophy, strategy, and key resources.

- Step 1: Agree upon purpose(s) and objectives for collaborating, a set of expected behaviors of acceptable collaboration, and the social space in which collaboration will take place.

- Step 2: Each participant shares course descriptions, resources, and key trends that may affect his or her teaching and learning.

○ Step 3: Both collectively and individually, reflect on shared information. As a group, identify key elements of each other's course design, delivery, assessment strategies, teaching philosophies, and challenges.

- Phase 2: Compare and contrast the similarities and differences between each other's approaches.

- Step 1: Collectively recommit to the shared purposes and objectives of collaborating (or update desired purposes/objectives if needed).

- Step 2: Based on earlier discussions, identify, compare, and contrast similarities and differences between each other's approaches. Discuss challenges and experiences, compare/contrast materials and approaches, trends to which individuals or programs are responding, etc.

- Step 3: Collectively and individually, reflect on similarities, differences, trends, and challenges. Ask questions as: what lessons do these experiences teach? What trends or challenges are most important to address? How can this information help us better prepare the next generation of IDs? 
- Phase 3: Integrate lessons learned into our individual teaching.

- Step 1: As individuals, determine objectives for course improvement activities. What should be improved in your course and why?

- Step 2: As individuals, update and improve your course outcomes, key assessments, activities, or materials. Base changes on previous discussions, with continual help from collaborators.

- Step 3: As individuals, reflect and gather evidence on your new course design. How well is it achieving your course improvement objectives? What went particularly well with process and why? What should be changed with process and how?

As space does not permit a lengthy discussion of this model, we only summarize how it illuminates in our own collaborative practices (readers interested in more details are encouraged to review our discussion above in light of our proposed model). First, we agreed upon a purpose for collaborating as we recognized that all three of us were facing similar challenges in preparing IDs to work in more complex environments, and wanted to learn from each other about addressing these challenges. Second, we shared course descriptions and resources as presented in our cases above. Third, we reflected with each other through multiple, technology-mediated conversations over a period of weeks, all of which led into cycles of comparing/contrasting our individual approaches, as described above. Finally, we are each integrating changes into our course practices using the ideas and even materials we shared with each other.

How might this model be used by other teachers of ID address the specific and substantive issues they face? As one answer to this question, it became clear as we discussed the differences between our approaches that some of the variance stemmed from how our programs 
viewed emerging trends in the areas of learning and instruction. We present three of the issues we identified, that may be facing other institutions as well, as suggestions for how readers might identify initial purposes by which they can begin cross-institutional collaboration efforts of their own.

Our understanding of learning is evolving. Recent advances in cognitive neuroscience point to the need for IDs to view and gain knowledge of learning in ways they have not done previously (Critchfield \& Twyman, 2014). Advances in neuroimaging technology and brain research continue to change our understanding of how and why people learn, and the traditional strategies which instructional designers have been trained to facilitate such learning (e.g., Hirumi et al., 2017). Additionally, the environments in which learning occurs will become more ubiquitous. The distinctions between face-to-face, online, and blended learning will continue to blur as emerging technologies continue to facilitate how we access, manipulate, store and disseminate information (Woo, Gosper, McNeill, Preston, Green, Phillips, 2008).

Our understanding of design as a field is evolving. Insights from traditional design disciplines such as architecture are providing instructional designers a greater understanding of how to address challenges using design as a mode of inquiry and not only as a process for product development (Nelson \& Stolterman, 2012). And as instructional designers solve problems they will be expected to be more creative, more innovative, and more willing to question the status quo (McDonald, 2016). One example of a design approach that facilitates this type of questioning is the approach known as presumptive design, which encourages designers to learn about environments in which they are working through the creation of prototypes that force the design team (including sponsors and stakeholders) to confront what they do not know about a situation. Through the experience of quick failure, designers can facilitate conversations about 
how to learn more about what they do not know, and how to compensate for constraints in their environment (Frishberg \& Lambdin, 2016).

Environments in which IDs work are evolving. Already people work for more organizations than those in previous generations, and will often work in multiple industries over the course of a career. Organizational structures continue to flatten (Meisenback \& Jensen, 2017). Modern development processes, such as agile development (Dingsøyr \& Moe, 2014), continue to accelerate the pace of product creation. More decisions are being made through big data (McAfee \& Brynjolfsson, 2012). All of this means instructional designers will need to demonstrate their value to the organization, be strong communicators, better consumers of information, and able to make rapid, flexible decisions that are aligned with a broad range of organizational needs.

\section{Conclusion}

In this paper we explored how cross-institution collaboration between teachers of ID can help them develop insights that improve their work as educators of the next generation of designers. Through reflection and discussion guided by the principles of action research and experiential learning, we studied our own instance of collaboration, and developed a model for how other ID educators can engage in similar collaboration themselves. This cyclical model of engaging, comparing/contrasting, and integrating lessons learned offers a systematic approach for collaborators to ask each other questions helpful for understanding the issues new instructional designers are likely to face. Our model also provides educators tools for discovering new approaches to address these issues that they can add to their own courses or programs.

Perhaps the most promising approaches to teaching ID are yet to be discovered.

Considering the dynamic environments in which designers of the future will work, ID educators 
will be expected to help their students have classroom experiences that closely align with the new demands those novices will face. Our task of preparing IDs to be highly innovative problem solvers, with the ability to navigate $21^{\text {st }}$ century environments, requires an equal level of innovation in our own teaching practices. The model of collaboration we propose will allow those teaching ID to work together in discovering what those innovative approaches may be, and how new approaches can be implemented for the benefits of students who will someday emerge as leaders in the field. 


\section{References}

Andrews, D. H. ( 1995). A comparative analysis of models of instructional design. In G. Anglin (Ed.), Instructional technology: Past, present and future (2nd ed., pp. 161-182).

Englewood, CO: Libraries Unlimited, Inc.

Atkinson, T. \& Hirumi, A. (2010). The Game Brain: What does the brain tell us about playing games in schools? In A. Hirumi (ed.). Playing Games in School: Using Simulations and Videogames for Primary and Secondary Education (pp. 57-73). Eugene, WA: International Society for Technology in Education.

Botturi, L. (2006). Design models as emergent features: An empirical study in communication and shared mental models in instruction. Canadian Journal of Learning and Technology, $32(2), 27-52$

Boling, E., \& Smith, K. M. (2014). Critical issues in studio pedagogy: Beyond the mystique and down to business. In B. Hokanson \& A. S. Gibbons (Eds.), Design in educational technology: Design thinking, design process, and the design studio (pp. 37-56). New York, NY: Springer.

Borkin, M. A., Vo, A. A., Bylinskii, Z., Isola, P., Sunkavalli, S., Oliva, A., \& Pfister, H. (2013). What makes a visualization memorable? IEEE Transactions on Visualization and Computer Graphics, 19(12), 2306-2315.

Brown A. H., \& Green T.D. (2016). The essentials of instructional design: Connecting fundamental principles with process and practice. New York, NY: Routledge.

Cennamo, K. (2016). What is studio? In E. Boling, R. A. Schwier, C. M. Gray, K. M. Smith, \& K. Campbell (Eds.), Studio teaching in higher education: Selected design cases (pp. 248259). New York, NY: Routledge. 
Clark, R. E. (2004). Design document for a guided experiential learning course. Submitted to satisfy contract DAAD 19-99-D-0046-0004 from TRADOC to the Institute for Creative Technologies and the Rossier School of Education, University of Southern California.

Clinton, G., \& Rieber, L. P. (2010). The studio experience at the University of Georgia: An example of constructionist learning for adults. Educational Technology Research and Development, 58(6), 755-780.

Colder B. (2011). Emulation as an integrating principle for cognition. Frontiers in Computational Neuroscience, 5(54).

Cox, S., \& Osguthorpe, R. T. (2003). How do instructional design professionals spend their time? TechTrends, 47(3), 45-47.

Dick, W., Carey, L., \& Carey, J.O., (2015). The systematic design of instruction (8th ed.). Boston, MA: Pearson.

Dirksen, J. (2016). Design for how people learn (2nd ed.). New York, NY: New Riders.

Dunne, J. (1993). Back to the rough ground: 'Phronesis' and 'techne' in modern philosophy and in Aristotle. Notre Dame, IN: University of Notre Dame Press.

Edmonds, G. S., Branch, R. C. \& Mukherjee, P. ( 1994.) A Conceptual Framework for comparing instructional design models. Educational Technology Research and Development, 42(4), 55-72.

Gagné, R. (1987). Instructional technology foundations. Hillsdale, NJ: Lawrence Erlbaum.

Gibbons, A. S. (2016). Evolving into studio. In E. Boling, R. A. Schwier, C. M. Gray, K. M. Smith, \& K. Campbell (Eds.), Studio teaching in higher education: Selected design cases (pp. 137-151). New York, NY: Routledge. 
Gibbons, A. S. (2013). An architectural approach to instructional design. New York. NY: Routledge.

Gustafson, K. L., \& Branch, R. M.(2002). Survey of instructional development models (4th ed). Syracuse, NY: Eric Clearinghouse on Information and Technology.

Hannafin, M. J., Hannafin, K.M., Land, S. M., \& Oliver, K. (1997). Grounded practice and the design of constructivist learning environments. Educational Technology Research and Development, 45(3), 101-117.

Hirumi, A., Johnson, K., Kleinsmith, A., Reyes, R., Rivera-Gutierrez, D., Kubovec, S., Bogert, K., Lok, B., \& Cendan, J. (2017). Advancing virtual patient simulations and experiential learning with InterPLAY: Examining how theory informs design and design informs theory. Journal of Applied Instructional Design, 6(1), 49-65. doi.org/10.289990/jaid2017.061005.

Hirumi, A. (Ed.) (2014a). Grounded Designs for Online and Hybrid Learning: Practical Guidelines for Educators and Instructional Designers. Book I-Design Fundamentals. Eugene, WA: International Society for Technology in Education.

Hirumi, A. (Ed.) (2014b). Grounded Designs for Online and Hybrid Learning: Practical Guidelines for Educators and Instructional Designers. Book II - Designs in Action. Eugene, WA: International Society for Technology in Education.

Hirumi, A. (2013). Three levels of planned e-learning interactions: A framework for grounding research and the design of e-learning programs. Quarterly Review of Distance Education, 14(1), 1-16.

Hirumi, A. (2002a). A framework for analyzing, designing and sequencing planned e-learning interactions. Quarterly Review of Distance Education, 3(2), 141-160. 
Hirumi, A. (2002b). The design and sequencing of e-learning interactions: A grounded approach. International Journal on E-Learning, 1(1), 19-27.

Hirumi, A., Johnson, K., Kleinsmith, A., Reyes, R., Rivera-Gutierrez, D., Kubovec, S., Bogert, K., Lok, B., \& Cendan, J. (2017). Advancing virtual patient simulations and experiential learning with InterPLAY: Examining how theory informs design and design informs theory. Journal of Applied Instructional Design, 6(1), 49-65. doi.org/10.289990/jaid2017.061005.

Hirumi, A., Lok, B., Johnson, T., Johnson, K., Rivera-Gutierrez, D., Ramsamooj, R., ...Cendan, J. (in press). Nerve, interplay, and design-based research: Advancing experiential learning and the design of virtual patient simulations. In J. M. Spector, B. B. Lockee, and M. D. Childress (Eds). Learning, Design, and Technology: An Interactional Compendium of Theory, Research, Practice, and Policy. New York, NY: Springer.

Krouse, A. (2015). Instructional design: More important than ever!. Journal of Nursing Education, 54(6), 304-3Larson, M. B., \& Lockee, B. B. (2009). Preparing instructional designers for different career environments: A case study. Educational Technology Research and Development, 57(1), 1-24.

Lindsey, L., \& Berger, N. (2009). Experiential approach to instruction. In C. Reigeluth and A. Carr-Chellman (Eds.). Instructional-design theories and models: Vol. 3. Building a common knowledge base (pp. 117-142), New York, NY: Routledge. 
McDonald, J. K. (2016). Embracing the danger: Accepting the implications of innovation. Educational Technology, 56(6), 14-17.

Merriam, S. B., \& Tisdell, E. J. (2016). Qualitative research: A guide to design and implementation (4th ed.). San Francisco, CA: Jossey-Bass.

Merriënboer, J., Clark, R. E., Croock, M. (2002). Blueprints for complex learning: The 4C/IDmodel. Educational Technology Research and Development, 50(2), 39-64.

Quinn, J. (1994). Connecting education and practice in an instructional design graduate program. Educational Technology Research and Development. 42(3), 71-82.

Rich, P. J., West, R. E., \& Warr, M. (2015). Innovating how we teach collaborative design through studio-based pedagogy. In M. A. Orey \& R. M. Branch (Eds.), Educational media and technology yearbook (Vol. 39, pp. 147-163). Switzerland: Springer International Publishing.

Salama, A. M. (1995). New trends in architectural education: Designing the design studio. Raleigh, NC: Tailored Text \& Unlimited Potential Publishing.

Schön, D. A. (1985). The design studio: An exploration of its traditions and potentials. London, England: RIBA Publications Limited.

Shambaugh, N. \& Magliaro, S. (2001) A reflexive model for teaching instructional design. Educational Technology, Research and Development, 49(2), 69-92.

Slagter van Tryon, P.J., \& Bishop, M.J. (2009) Theoretical foundations for enhancing social connectedness in online learning environments. Distance Education, 30(3), 291-315.

Slagter van Tryon, P.J., \& Bishop, M.J. (2006). Identifying e-mmediacy strategies for web-based instruction: A Delphi study. Quarterly Review of Distance Education, 7(1), 49-62. 
van Rooij, S. W. (2010). Project management in instructional design: ADDIE is not enough, British Journal of Educational Technology, 41(5), 852-864.

Wenger, E. (1998). Communities of practice: Learning, meaning, and identity. New York, NY: Cambridge University Press.

Winn, W. (1997). Advantages of a theory-based curriculum in instructional technology. Educational Technology, 37(1), 34-41.

Yanchar, S. C., South, J. B., Williams, D. D., Allen, S., \& Wilson, B. G. (2010). Struggling with theory? A qualitative investigation of conceptual tool use in instructional design. Educational Technology Research and Development, 58(1), 39-60. doi:10.1007/s11423009-9129-6

Young, A. C., Reiser, R. A. \& Dick, W. (1998). Do superior teachers employ systematic instructional planning procedures? A descriptive study. Educational Technology Research and Development, 46(2), 65-78.

Woo, K., Gosper, M., McNeill, M., Preston, G., Green, D., \& Phillips, R. (2008). Web-based lecture technologies: blurring the boundaries between face-to-face and distance learning. Research in Learning Technology, 16(2). doi:https://doi.org/10.3402/rlt.v16i2.10887 

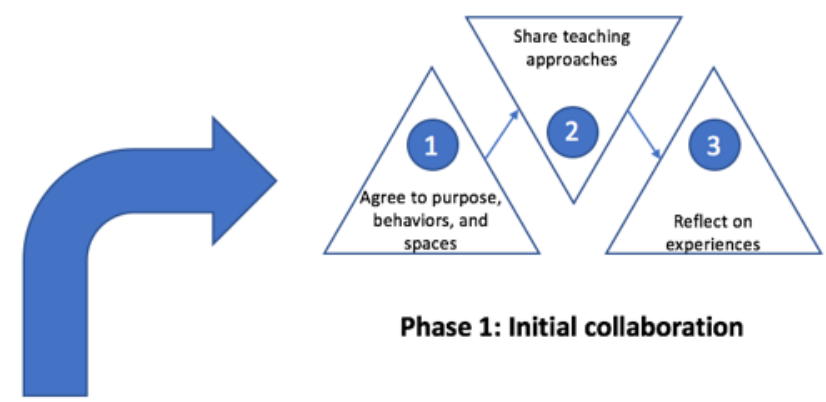

Phase 1: Initial collaboration
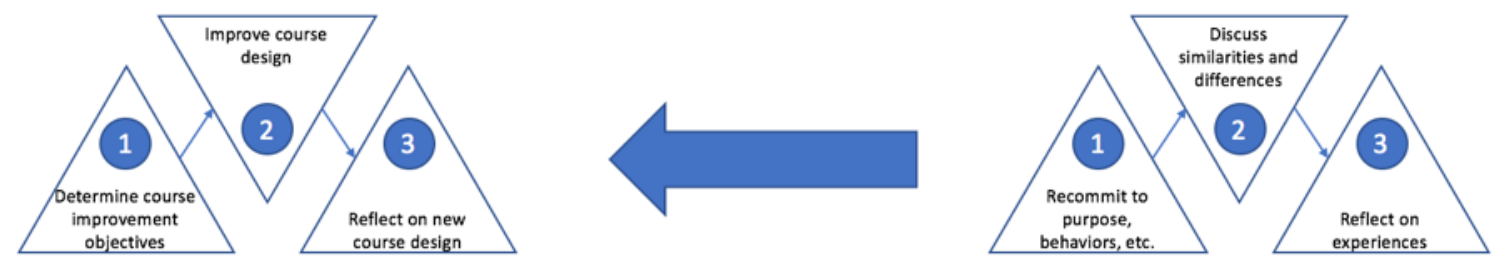

Phase 3: Integration

Phase 2: Compare/contrast

Figure 1. A model for cross-institution faculty collaboration. 